\title{
Bubble Nasal CPAP, Early Surfactant Treatment, and Rapid Extubation Are Associated With Decreased Incidence of Bronchopulmonary Dysplasia in Very-Low-Birth-Weight Newborns: Efficacy and Safety Considerations
}

\author{
Charles A Friedman MD, Robert C Menchaca MBA RRT, Mary C Baker RN-CIC, \\ Clarissa K Rivas RRT, Raymond N Laberge RRT, Enrique H Rios MD, Syed H Haider MD, \\ Edgar J Romero MD, Elizabeth B Eason MD, J Kennard Fraley MPH, \\ and Mesfin Woldesenbet MD
}

\begin{abstract}
BACKGROUND: Current literature has been inconsistent in demonstrating that minimizing the duration of mechanical ventilation in very-low-birth-weight (VLBW) newborns reduces lung damage. OBJECTIVE: To determine if introduction of bubble nasal CPAP (bnCPAP), early surfactant treatment, and rapid extubation (combined bnCPAP strategy) in our community-based neonatal ICU reduced bronchopulmonary dysplasia (BPD). METHODS: This was a 7-year retrospective, single-institution review of respiratory outcomes in $633 \mathrm{VLBW}$ babies before and after introduction of the combined bnCPAP strategy. Coincident changes in newborn care were taken into account with a logistic regression model. RESULTS: The average percentage of VLBW newborns with BPD decreased to $25.8 \%$ from $35.4 \%(P=.02)$, reaching a minimum in the last post-bnCPAP year of $22.1 \%(P=.02)$. When other coincident changes in newborn care during the study years were taken into account, VLBW babies in the post-bnCPAP years had a $43 \%$ lower chance of developing BPD $(P=.003$, odds ratio $0.43,95 \% \mathrm{CI} 0.25-0.75)$. Decreases occurred in mechanical ventilation and the percentage of infants discharged on diuretics and on supplemental oxygen. Among the subset of extremely-low-birth-weight newborns, improved respiratory outcomes in the post-bnCPAP years, as compared to outcomes in the pre-bnCPAP years, included an increase in the percentage alive and off mechanical ventilation at 1 week postnatal age $(P<.001)$, a more rapid extubation rate $(P<.03)$, a decrease in the median days on mechanical ventilation $(P=.002)$, and a decrease in the percentage with BPD plus died $(P=.01)$. Post-bnCPAP extremely-low-birth-weight babies had a statistically significant decrease in retinopathy of prematurity, an increase in low-grade intraventricular hemorrhage, and a decrease in ductal ligations. CONCLUSIONS: A combined BnCPAP strategy may contribute to a reduction of BPD, after adjusting for concurrent treatments. Key words: bubble nasal CPAP; very low birth weight newborns; mechanical ventilation; inflammatory lung disease; retinopathy of prematurity; intraventricular hemorrhage; patent ductus arteriosus; diuretics; vitamin A; indomethacin. [Respir Care 2013;58(7):1134-1142. () 2013 Daedalus Enterprises]
\end{abstract}

\footnotetext{
The authors are affiliated with the Division of Neonatology, Memorial Hermann Southwest Hospital, Houston, Texas, with the exception of Mr Fraley, who is affiliated with the Department of Pediatrics, Baylor College of Medicine, Houston, Texas. Drs Friedman, Rios, Haider, Romero, Eason, and Woldesenbet are also affiliated with Pediatrix Medical Group of Houston, Houston, Texas. Mr Menchaca, Ms Rivas, and Mr Laberge are also affiliated with the Division of Respiratory Therapy, Memorial Hermann Southwest Hospital.
}

The authors have disclosed no conflicts of interest.

Correspondence: Charles A Friedman MD, Pediatrix Medical Group of Houston, 7777 Southwest Freeway, Suite 310, Houston TX 77074. Email: charlesfriedman@comcast.net.

DOI: $10.4187 /$ respcare. 01998 


\section{Introduction}

Bronchopulmonary dysplasia (BPD) remains an important complication of the care of very-low-birth-weight (VLBW) newborns in neonatal ICUs (NICUs). The incidence of VLBW is rising; therefore, we can expect more preterm babies with BPD. ${ }^{1}$ Of the 4.26 million births annually in the United States, $1.48 \%$ or 63,000 are of VLBW. ${ }^{1}$ The incidence of BPD in these babies varies widely among institutions in the Vermont-Oxford Network, ${ }^{2-6}$ from $10 \%$ to over $40 \%$, which is significantly higher than the $4 \%$ rate reported from Columbia Babies' Hospital in New York, 5,7 where bubble nasal CPAP (bnCPAP) is used.

At our institution the average incidence of BPD from 2003 to 2006 was $35.4 \%$, which was higher than the Vermont-Oxford Network BPD rate at that time (26.9\%). We therefore sought methods to decrease our BPD rate. A literature review of interventions intended to ameliorate BPD in VLBW newborns, including delivery room intubation and surfactant administration and target levels of oxygen saturation and nasal CPAP, have shown mixed results in reducing BPD. Some studies have reported no reduction in BPD rate, $2,8,9$ while others have supported such reductions. ${ }^{5,10-12}$

\section{See the Related Editorial on Page 1257}

We attempted to decrease our rate of BPD without increasing mortality or morbidity, ${ }^{11}$ by combining bnCPAP in the delivery room with early surfactant use and immediate extubation to bnCPAP (the intubation for surfactant and immediate extubation [INSURE] strategy) and early extubation to bnCPAP for those babies weaning from mechanical ventilation. ${ }^{12}$

It was our hope that a single institution with a large number of NICU VLBW babies could reduce the incidence of BPD over time. We accounted for other changes in clinical practice concomitant with the introduction of bnCPAP that could potentially influence our institutional rate of BPD or other outcomes of NICU care.

\section{Methods}

We hypothesized as our primary outcome that the introduction of bnCPAP, early surfactant treatment, and a rapid extubation protocol (during the bnCPAP years) would be associated with a decrease in BPD or BPD plus death. BPD was defined as the need for any supplemental oxygen at 36 weeks corrected gestational age. Severe BPD was defined as mechanical ventilation support at 36 weeks corrected gestational age.

Respiratory outcome data were analyzed to compare the 3 pre-bnCPAP reference years (1-3, when no bnCPAP

\section{QUICK LOOK}

\section{Current knowledge}

Minimizing the need for and duration of mechanical ventilation in very-low-birth-weight infants reduces the risk of ventilator-induced lung injury. Delivery room treatment includes surfactant administration and noninvasive ventilation, but the impact of these therapies on the rate of bronchopulmonary dysplasia has not been clearly defined.

\section{What this paper contributes to our knowledge}

In this single-center, retrospective study, a strategy of early surfactant use, bubble CPAP, and rapid extubation in very-low-birth-weight infants was associated with less bronchopulmonary dysplasia. This finding should be confirmed in a randomized controlled trial.

was used and babies intubated for surfactant treatment were not extubated immediately) to the last 3 bnCPAP years (5-7), allowing year 4 as a transition period between no bnCPAP and bnCPAP use.

Secondary outcomes included overall survival to discharge, median number of days on mechanical ventilation, the proportion of VLBW babies discharged on oxygen or diuretics, and the proportion of extremely-low-birth-weight (ELBW) babies alive and not receiving mechanical ventilation at 1 week of postnatal age.

The medical records of all VLBW newborns admitted to our NICU over a 7-year period, from November 2003 through November 2010, were eligible for review. Newborns treated during the first 3 years before the introduction of bnCPAP served as historical reference controls. Subsequent study years 5 through 7 occurred after bnCPAP and the INSURE strategy were introduced in year 4, which we considered as a transition year. Newborns with an airway anomaly or important congenital heart disease were excluded.

In the historical control years $1-3$, only machine nasal CPAP was used. Nasal CPAP was not offered in the delivery room, and there was no explicit attempt at immediate extubation for babies receiving surfactant.

A Hudson bnCPAP protocol was initiated in November 2006, after the respiratory therapy, nursing, and physician staff had become familiar with the equipment and had been educated to: bnCPAP in the delivery room for VLBW babies breathing spontaneously; intubation and delivery room instillation of surfactant or within 2 hours of birth for those judged to have substantial respiratory distress followed by immediate extubation to bnCPAP ${ }^{12}$ after heart rate and oxygen saturation were stable and the baby was 
breathing spontaneously (no sedatives or paralytics were used); early extubation to bnCPAP for babies receiving mechanical ventilation with $\mathrm{F}_{\mathrm{IO}_{2}}$ of $<0.30$ on conventional ventilator rate of 30 breaths/min or mean airway pressure of $<8 \mathrm{~cm} \mathrm{H}_{2} \mathrm{O}$; for subjects managed on high frequency oscillatory ventilation, early extubation for amplitude less than 20; for babies managed on jet ventilation, early extubation for positive inspiratory pressure less than $20 \mathrm{~cm} \mathrm{H}_{2} \mathrm{O}$ and jet rate of 240/min. VLBW babies had target oxygen saturation of $85 \%$ to $95 \%$ set during the 7 years of this study; review of the technique of application and maintenance of Hudson prongs by JT Wung MD of Columbia University, New York, on site in our NICU after 5 months of bnCPAP use. This review was during study year 4 , which was therefore considered a transition year, allowing time for the staff to adjust to using bnCPAP.

There were 2 technical challenges during implementation of bnCPAP: maintaining the bubbling, and preventing nasal septal necrosis. We found 2 materials that solved these problems. One was a duoderm type material that helps to seal airway leaks around the nares (Cannulaide, Beevers, McMinnville, Oregon). The second was an ultrathin hydrocolloid wound dressing material (Replicare Thin, Smith and Nephew, St Petersburg, Florida), which had to be cut into the desired shape for the infant's nose. It also made an excellent seal. The nasal prongs needed to be inserted minimally into either material in order to achieve a seal. These materials helped avoid contact with the septum, minimizing abrasions and improved sealing for continued bubbling.

Attending clinicians, both before and after bnCPAP was introduced, decided by clinical criteria if babies in respiratory distress in the delivery room required intubation, surfactant, and mechanical ventilation, or (in the bnCPAP years) could be managed with nasal CPAP, and if newborns extubated to nasal CPAP were failing and required reintubation. Criteria included the goals of maintaining $\mathrm{pH} \geq 7.25, \mathrm{P}_{\mathrm{CO}_{2}}<70 \mathrm{~mm} \mathrm{Hg}$, and avoiding frequent apneas requiring bagging or markedly increased work of breathing. All newborns in the bnCPAP group were managed with 5-6 $\mathrm{cm} \mathrm{H}_{2} \mathrm{O}$ pressure and 5-6 L/min flow. Newborns in the retrospective historical control cohort were extubated, at the attending physician's discretion, either to ventilator-driven nasal CPAP with $4-8 \mathrm{~cm} \mathrm{H}_{2} \mathrm{O}$ pressure or nasal cannula at a flow of up to $2 \mathrm{~L} / \mathrm{min}$. In the postbnCPAP years babies were weaned from bnCPAP when they were $\geq 32$ weeks corrected gestational age and on bnCPAP and in room air for at least 2 days, as at Columbia University, New York City (personal communication, JT Wung MD). Nasal intermittent positive-pressure ventilation was not used before or after bnCPAP in this study.
We calculated the proportion of VLBW and ELBW newborns receiving mechanical ventilation each day during the first month after birth, as well as median days on mechanical ventilation.

Primary outcome and secondary comorbidities were compared using the 2-tailed $t$ test for continuous variables, and the chi-square or Fisher exact test for proportional differences, where appropriate. Odds ratios (ORs) and 95\% CIs were calculated for categorical and continuous data. For continuous variables displaying a non-normal pattern, the Mann-Whitney U test for differences in medians was used. Demographic data used to adjust for confounding variables included birth weight, gestational age, sex, outborn status, a diagnosis of chorioamnionitis, and the use of prenatal steroids. The Tukey multiple correction adjustment was used for multiple hypothesis testing.

Possible adverse outcomes associated with bnCPAP were compared for the study years. These included nasal abrasions, use of postnatal steroids, and the proportion of newborns with respiratory complications of pneumothorax (ventilator or nasal CPAP-associated) and pulmonary hemorrhage, clinically important patent ductus arteriosus (PDA), grade of intraventricular hemorrhage (IVH grades 1-2 were considered low-grade and IVH grades 3-4 were considered high-grade) or periventricular leukomalacia, stage of retinopathy of prematurity (ROP), necrotizing enterocolitis $\geq$ stage 2 , and death. Possible confounding variables introduced during the study years (vitamin A prophylaxis for BPD, indomethacin prophylaxis for IVH, and changes in rates of surgical ligation of PDA) were analyzed for their possible impact on BPD rate relative to the introduction of bnCPAP, by a binary logistic regression model. Data were abstracted from the Vermont-Oxford Network database maintained by the hospital. For patients transferred from our facility for a higher level of care (for surgery or multispecialty consultation), the common database shared with our referral facility was queried to ascertain respiratory outcomes.

Patient confidentiality was assured by examination of Vermont-Oxford Network data after stripping data of all patient identifiers. The institutional review board of our health system approved this study.

\section{Results}

Charts of 633 VLBW newborns were reviewed: 239 in years $1-3$ as the pre-bnCPAP control years, 99 in the transition year 4, and 295 in years 5-7 as the post-bnCPAP test years. There were 241 newborns $(45.1 \%$ of the 534 study newborns) with ELBW (Table 1). The percentage of newborns who required transfer out of our unit (for surgical or multispecialty evaluation) was significantly higher in the post-bnCPAP years than in the pre-bnCPAP years, and there was a concomitant increase in subjects trans- 
Table 1. Demographic Data Comparison of Very-Low-BirthWeight Newborns Before and After Implementation of a Bubble Nasal CPAP Strategy

\begin{tabular}{lccc}
\hline \hline & Before & After & $P$ \\
\hline Study sample size & 239 & 295 & \\
Birth weight $<1,001$ g, no. $(\%)$ & $98(40.9)$ & $143(48.5)$ & .26 \\
Birth weight, average \pm SD g & $1,052 \pm 270$ & $1,013 \pm 305$ & .12 \\
EGA, average \pm SD weeks & $27.9 \pm 2.6$ & $27.5 \pm 3.0$ & .09 \\
Male, \% & 48.8 & 47.8 & .79 \\
Transferred out, \% & 4.6 & 12.9 & $<.001 *$ \\
Transferred in, \% & 12.8 & 23.7 & $.002 \dagger$ \\
Prenatal steroids, \% & 58.7 & 49.5 & $.04 \ddagger$ \\
Chorioamnionitis, \% & 4.8 & 7.1 & .27 \\
& & & \\
* Adjusted odds ratio 3.06, 95\% CI 1.53-6.13. & & & \\
$\dagger$ Odds ratio 3.53, 95\% CI 2.22-5.61. & & & \\
¥ Odds ratio 0.69, 95\% CI 0.49-0.97. & & & \\
§ Based on obstetric clinical diagnosis. & & & \\
EGA = estimated gestational age at birth & & & \\
\hline
\end{tabular}

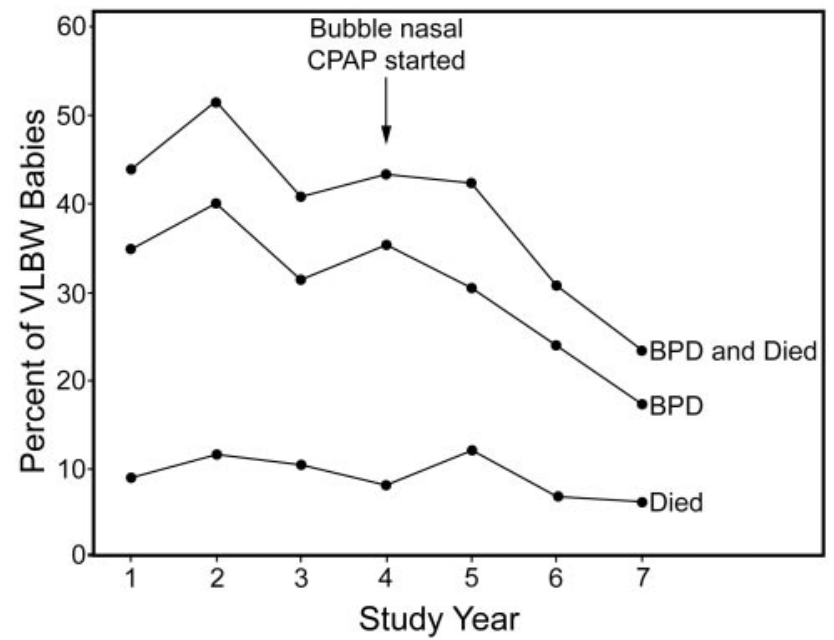

Fig. 1. Percent of very-low-birth-weight (VLBW) babies with bronchopulmonary dysplasia (BPD), died with BPD, and died, before and after implementation of the bubble nasal CPAP strategy.

ferred into our unit for level 3 care. There was a decrease in the percent receiving prenatal steroids in the postbnCPAP years.

Data on the respiratory status at 36 weeks corrected gestational age and at discharge for 21 subjects (3.3\%) were unavailable for analysis, but the proportion of babies missing data were not statistically different between the control and bnCPAP years.

Average days on nasal CPAP increased significantly in the post-bnCPAP years $(26.9 \pm 19.4 \mathrm{~d})$, compared to the pre-bnCPAP reference years $(14.2 \pm 11.8 \mathrm{~d})$ when only ventilator nasal CPAP was used $(P<.001,95 \% \mathrm{CI}-15.6$ to -9.9$)$.

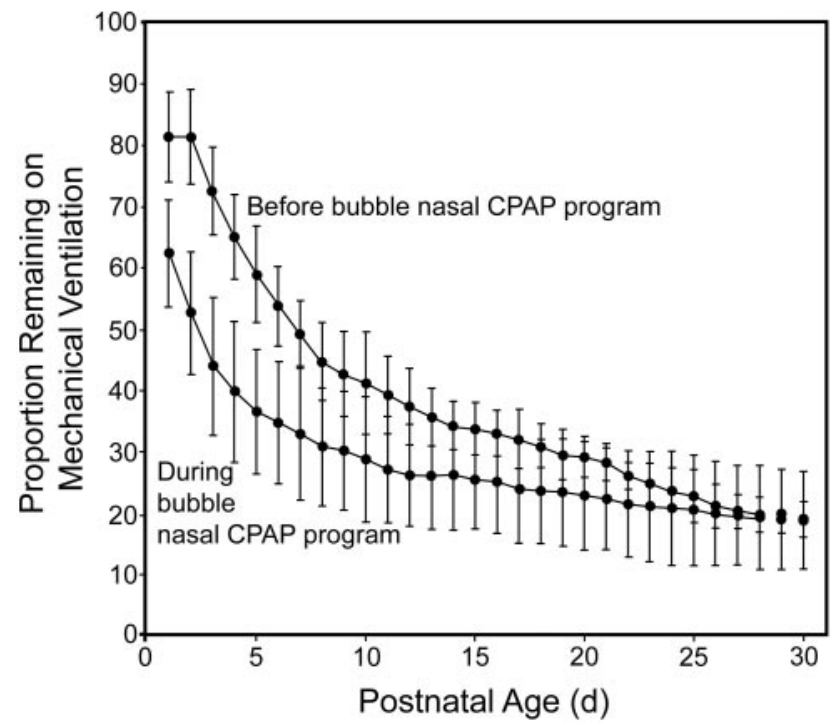

Fig. 2. Proportion of very-low-birth-weight newborns mechanically ventilated to 30 days after birth, before and after implementation of the bubble nasal CPAP strategy.

\section{Efficacy of bnCPAP in VLBW Babies}

To study the efficacy of the increased use of bnCPAP in improving respiratory outcomes, we compared outcome data for newborns in the pre- and post-bnCPAP study years, allowing for year 4 as the transition year.

The average BPD rate in the post-bnCPAP years decreased significantly, compared to the average BPD rate in the pre-bnCPAP reference years: $25.8 \%$ versus $35.4 \%$, respectively $(P=.02)$. There was no significant difference in the percent who died: $11.4 \%$ versus $10.7 \%(P=.92)$. The combined variable of percent BPD plus deaths in the post-bnCPAP years was less than in the pre-bnCPAP years: $37.2 \%$ versus $46.1 \%(P=.04)$ (Fig. 1).

The BPD rate and BPD plus died rate reached a minimum in the seventh year (the fourth year after bnCPAP was started): $22.1 \%(P=.02)$ and $28.5 \%(P=.007)$, respectively, comparing the last post-bnCPAP year to the average BPD rate in the pre-bnCPAP years (see Fig. 1).

Fewer required mechanical ventilation on the first postnatal day in the post-bnCPAP study years than in prebnCPAP years $(P<.001)$ (Fig. 2) and remained significantly fewer through postnatal day 20 . The median days on mechanical ventilation decreased as well after bnCPAP $(P<.001)$ (Table 2). A significantly lower percentage of post- than pre- bnCPAP VLBW babies were discharged on supplemental oxygen or discharged on diuretics.

\section{Efficacy of bnCPAP in the ELBW Subset}

A separate analysis of the subset of ELBW newborns showed no difference in the percent of babies on mechan- 
Table 2. Secondary Respiratory Outcomes for Very-Low-Birth-Weight Newborns Before and After Implementation of a Bubble Nasal CPAP Strategy

\begin{tabular}{|c|c|c|c|c|c|}
\hline & $\begin{array}{c}\text { Before } \\
n=239\end{array}$ & $\begin{array}{c}\text { After } \\
n=295\end{array}$ & $P$ & $\begin{array}{c}\text { Adjusted } \\
\text { Odds Ratio }\end{array}$ & $95 \% \mathrm{CI}$ \\
\hline Median days on mechanical ventilation & 5.00 & 1.00 & $<.001 *$ & & -3.00 to -1.00 \\
\hline Discharged on supplemental $\mathrm{O}_{2}$ & 32.5 & 19.0 & $<.001$ & 0.48 & $0.32-0.71$ \\
\hline Discharged on diuretics & 9.3 & 3.4 & .006 & 0.35 & $0.16-0.74$ \\
\hline Re-intubated for CPAP failure & 30.2 & 32.9 & .47 & 0.88 & $0.61-1.27$ \\
\hline Pulmonary hemorrhage & 4.7 & 4.4 & .84 & 1.05 & $0.46-2.38$ \\
\hline Pneumothorax $\dagger$ & 2.9 & 4.8 & .37 & 1.65 & $0.65-4.15$ \\
\hline Nasal abrasions $\ddagger$ & 1.2 & 6.4 & .06 & 5.85 & $0.77-44.3$ \\
\hline Postnatal steroids $\ddagger \S$ & 7.0 & 14.9 & .07 & 2.33 & $0.96-5.68$ \\
\hline \multicolumn{6}{|c|}{$\begin{array}{l}\text { All values except median days are percentage. } \\
* \text { Calculated by Mann-Whitney U test for non-parametric data. } \\
\dagger \text { Includes ventilator-associated and CPAP-associated pneumothoraces. } \\
\text { ‡ Comparing the bnCPAP years } 5-7 \text { to pre-bnCPAP year } 3 \text { (data for pre-bnCPAP years } 1 \text { and } 2 \text { not available). } \\
\S \text { Mainly hydrocortisone for extubation in the bnCPAP years (data for pre-bnCPAP years } 1 \text { and } 2 \text { not available). } \\
\text { bnCPAP = bubble nasal CPAP }\end{array}$} \\
\hline
\end{tabular}

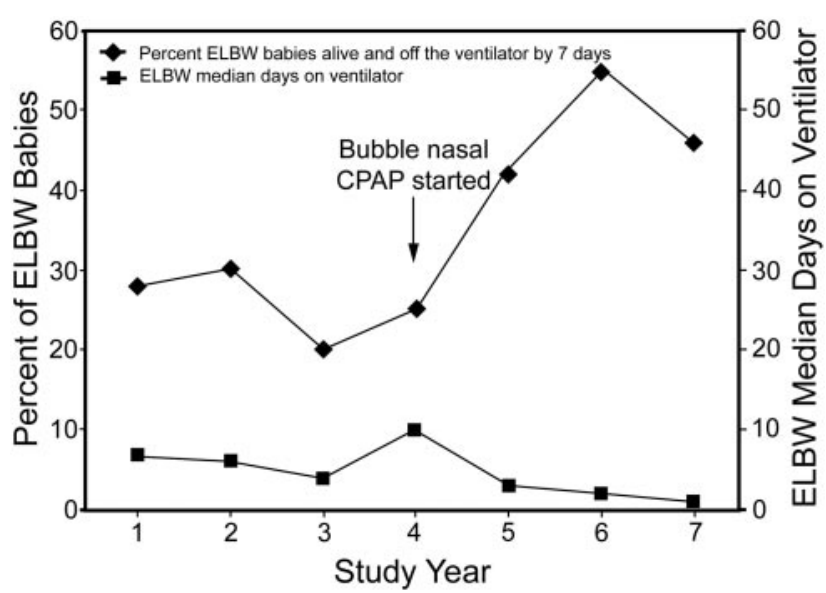

Fig. 3. Percent of extremely-low-birth-weight (ELBW) babies alive and off mechanical ventilation at 7 days, and median days on mechanical ventilation for ELBW babies, before and after implementation of the bubble nasal CPAP strategy.

ical ventilation in the first 2 post-natal days in the pre- and post-bnCPAP years, but statistically fewer remained on mechanical ventilation from day 3 through day 25 after bnCPAP than before bnCPAP $(P<.03)$. Significantly more ELBW babies survived to 7 days without mechanical ventilation in the post-bnCPAP years than in the prebnCPAP years $(P<.001)$, and the median days on mechanical ventilation decreased $(P=.002)$ (Fig. 3).

The percent of ELBW babies with BPD was not statistically different in the post-bnCPAP years than in the prebnCPAP years $(32.2 \%$ versus $42.3 \%, P=.11$, OR 0.65 , 95\% CI $0.38-1.09)$ nor the percent who died $(23.1 \%$ versus $28.9 \%$, respectively, $P=.34$, OR 0.74 , $95 \%$ CI $0.42-$ 1.31). However, the combined parameter of percent BPD plus died was significantly lower: $55.3 \%$ versus $71.2 \%$ $(P=.01$, OR $0.50,95 \%$ CI 0.29 to 0.85$)$.

Severe BPD (ventilator dependence at 36 weeks corrected gestational age) occurred only in ELBW babies, and was not significantly different in the pre- and post-bnCPAP ELBW cohorts: $6.1 \%$ and $4.9 \%$, respectively $(P=.77$, OR $0.79,95 \%$ CI $0.26-2.42$ ).

In both the pre- and post-bnCPAP cohorts the failure of nasal CPAP was almost exclusively in ELBW newborns, with $53.0 \%$ of those $\leq 1,000 \mathrm{~g}$ birth weight requiring reintubation, compared to $1.4 \%$ of those $>1,000 \mathrm{~g}$. The efficacy of nasal CPAP in the pre-bnCPAP and post-bnCPAP years was limited by reintubations, which did not differ between the 2 cohorts: $30.2 \%$ and $32.9 \%$, respectively $(P=.47)$. Apnea was the main reason for reintubation in both cohorts, with nasal abrasions accounting for a nonsignificant difference of $3.8 \%$ and $6.0 \%$ of reintubations in the pre- and postbnCPAP years, respectively $(P>.99)$.

\section{Safety Considerations of bnCPAP}

To study the safety of introducing bnCPAP to improve respiratory outcomes, we compared the incidence of pneumothoraces, reintubations because of failed nasal CPAP, nasal abrasions, postnatal steroid use, and pulmonary hemorrhages in VLBW babies before and after the introduction of bnCPAP. No significant differences were found (Table 3). Data for nasal abrasions and postnatal steroids were not available for the first 2 pre-bnCPAP years.

There was an increase in the percent of low-grade IVH in the post-bnCPAP years, compared to the pre-bnCPAP years, but no significant differences in high-grade IVH or any-grade IVH between the pre- and post- bnCPAP study years (see Table 3 ). Over all years, $62.9 \%$ of grade $1-2$ 
Table 3. Secondary Outcomes of Very-Low-Birth-Weight Newborns Before and After Implementation of a Bubble Nasal CPAP Strategy

\begin{tabular}{|c|c|c|c|c|c|}
\hline & \multicolumn{2}{|c|}{ Percentage } & \multirow[b]{2}{*}{$P$} & \multirow{2}{*}{$\begin{array}{c}\text { Adjusted } \\
\text { Odds Ratio }\end{array}$} & \multirow[b]{2}{*}{$95 \% \mathrm{CI}$} \\
\hline & $\begin{array}{c}\text { Before } \\
n=239\end{array}$ & $\begin{array}{c}\text { After } \\
n=295\end{array}$ & & & \\
\hline Vitamin A prophylaxis* & 16.2 & 48.8 & $<.001$ & 4.89 & $3.24-7.38$ \\
\hline Indomethacin prophylaxis $\dagger$ & 0 & 13.9 & $<.001$ & & \\
\hline PDA ligation & 19.3 & 3.4 & $<.001$ & 0.15 & $0.07-0.29$ \\
\hline \multicolumn{6}{|l|}{ IVH grade } \\
\hline $1-2$ & 4.1 & 10.5 & .008 & 2.69 & $1.29-5.60$ \\
\hline $3-4$ & 12.9 & 11.2 & .40 & 0.85 & $0.50-1.42$ \\
\hline Any grade & 17.0 & 21.6 & .19 & 1.34 & $0.86-2.06$ \\
\hline \multicolumn{6}{|l|}{ ROP stage } \\
\hline $1-2$ & 38.5 & 23.7 & $<.001$ & 0.50 & $0.34-0.72$ \\
\hline $3-4$ & 6.7 & 4.4 & .26 & 0.64 & $0.30-1.36$ \\
\hline Any stage & 45.2 & 28.1 & $<.001$ & 0.47 & $0.33-0.68$ \\
\hline NEC $\geq$ stage 2 & 17.9 & 13.2 & .13 & 0.69 & $0.43-1.11$ \\
\hline \multicolumn{6}{|c|}{$\begin{array}{l}\text { * Given for prevention of chronic lung disease. } \\
\dagger \text { Given for prevention of intraventricular hemorrhage. } \\
\text { PDA = patent ductus arteriosus } \\
\text { IVH = intraventricular hemorrhage } \\
\text { ROP = retinopathy of prematurity } \\
\text { NEC = necrotizing enterocolitis }\end{array}$} \\
\hline
\end{tabular}

IVH and $92.3 \%$ of grade 3-4 IVH occurred in ELBW babies. There was no significant difference in the percent distribution of IVH grades between pre-bnCPAP and postbnCPAP ELBW babies. There was no significant difference in the percent of VLBW newborns with a diagnosis of necrotizing enterocolitis $\geq$ stage 2 during the study years.

Significantly fewer babies in the post-bnCPAP years were diagnosed with low stage, or any stage ROP than in the pre-bnCPAP years (see Table 3), but there was no statistically significant difference in higher stage ROP during the study years. Of all severe ROP (stages 3-4) in the pre- and post-bnCPAP cohorts, $87.8 \%$ and $92.3 \%$, respectively, occurred in ELBW babies. Among ELBW babies with severe ROP there was no statistically significant difference between the pre- and post-bnCPAP cohorts: $14.3 \%$ and $8.4 \%$, respectively $(P=.20$, OR $0.55,95 \%$ CI $0.24-1.24)$.

\section{Coincident Clinical Changes}

Several relevant changes in clinical care of VLBW newborns occurred during the study years coincident with introduction on bnCPAP. Beginning in the fifth study year, ELBW newborns began receiving prophylactic indomethacin for prevention of IVH, whereas no babies in the prebnCPAP years received prophylactic indomethacin. As a result, there was a significant decline in the percentage of subjects undergoing PDA ligation in the post-bnCPAP years, compared to those in the pre-bnCPAP years. There was also an increase in the use of vitamin A prophylaxis for prevention of BPD, beginning during the pre-bnCPAP third year of the study (see Table 3).
Because of these changes in practice concurrent with institution of bnCPAP, a binary logistic regression model of the confounding effects of estimated gestational age, transfers in, sex, increase in vitamin A use, indomethacin prophylaxis, and decrease in PDA ligation was constructed. Taking these into account, the model confirmed a significant reduction in BPD associated with bnCPAP (Table 4).

\section{Discussion}

In this single community-based institution retrospective study of VLBW newborns we showed that reductions in mechanical ventilation, BPD, diuretic use, and discharges on supplemental oxygen were associated with a strategy that combined bnCPAP in the delivery room, early surfactant use followed by immediate extubation, and rapid weaning from mechanical ventilation.

The resulting significant improvement in respiratory outcomes contrasts with several published reports, which will be discussed below. Our large patient population of over 600 babies and longer data collection period ${ }^{11}$ may explain our positive results. This allowed enough time to transition our staff from reliance on mechanical ventilation to support VLBW newborns with respiratory distress to bnCPAP. Barriers toward more rapid improvements were likely due to challenges in educating personnel that mechanical ventilation can safely be avoided in spontaneously breathing babies.

Our data extend a study ${ }^{13}$ involving nearly 300 VLBW newborns over 2 years. This report combined bnCPAP 
Table 4. Logistic Regression Model Comparing Clinical Parameters With the Primary Outcome* Before and After Implementation of a Bubble Nasal CPAP Strategy

\begin{tabular}{lccc}
\hline \hline & $P$ & $\begin{array}{c}\text { Adjusted } \\
\text { Odds Ratio }\end{array}$ & $95 \%$ CI \\
\hline EGA & $<.001$ & 0.73 & $0.65-0.83$ \\
ELBW & .27 & 1.61 & $0.69-3.79$ \\
Prenatal steroids & .055 & 1.63 & $0.99-2.70$ \\
Chorioamnionitis & .31 & 1.79 & $0.58-5.52$ \\
Transfers in & .19 & 162 & $0.79-3.32$ \\
Male sex & .007 & 1.89 & $1.19-3.00$ \\
Vitamin A prophylaxis & .045 & 1.91 & $1.02-3.61$ \\
Indomethacin prophylaxis & .10 & 1.81 & $0.88-3.71$ \\
PDA ligation & $<.001$ & 5.05 & $2.23-11.44$ \\
Bubble nasal CPAP cohort ${ }^{1}$ & .003 & 0.43 & $0.25-0.75$
\end{tabular}

\footnotetext{
* The primary outcome was bronchopulmonary dysplasia (oxygen supplementation a

36 weeks corrected gestational age).

EGA = estimated gestational age at birth

ELBW $=$ extremely low birth weight $(\leq 1,000 \mathrm{~g})$

$\mathrm{PDA}=$ patent ductus arteriosus
}

with early surfactant treatment, which reduced the need for mechanical ventilation and decreased BPD. However, no improvement in respiratory outcome was found in their ELBW subset, comprising $<150$ subjects. The 241 ELBW babies in our study had a significant reduction in some parameters of respiratory disease after bnCPAP was introduced. These included alive and off mechanical ventilation at 7 days, a more rapid extubation rate compared to ELBW in the pre-bnCPAP years, a decrease in median days on mechanical ventilation, and a decrease in BPD-plus-died parameter but not in BPD itself. This may be due to the inability so far to reduce the proportion of ELBW newborns receiving mechanical ventilation on the first postnatal day. ${ }^{7}$ Also about half of the ELBW babies ultimately failed bnCPAP and required reintubation, mainly due to apnea. This may account for the fact that the percent of ELBW babies with severe BPD (ventilator dependent) did not change over the 7-year study period. We did not compare the time to re-extubation in the pre- and post-bnCPAP cohorts as a separate subgroup. However, those ELBW babies in the post-bnCPAP years requiring reintubation for apnea were probably more likely to be re-extubated back to bnCPAP sooner, as demonstrated in a more rapid extubation rate for the post-bnCPAP ELBW group as a whole.

A retrospective study ${ }^{14}$ similar to ours collected data over 4 years, combining several therapeutic changes, including early surfactant therapy and nasal CPAP. The authors demonstrated decreases in mechanical ventilation, BPD rate, and discharges home on oxygen therapy in ELBW babies. However, this study differed from ours because the authors employed ventilator-driven nasal CPAP rather than bnCPAP. They found an increase in PDA requiring ligation rather than the marked decrease in ligations we report.
This differing result may be explained by our use of indomethacin as prophylaxis rather than as therapy. ${ }^{15}$

Our study, besides its retrospective nature, differs from the recent SUPPORT trial ${ }^{16}$ because we used only bubble nasal CPAP. The SUPPORT trial did not specify which type of CPAP was used. We also did not vary the oxygen saturation parameters during the 7 years of our study, as was done in the SUPPORT trial and others. ${ }^{14}$

The sustained improvements we observed in respiratory outcomes for VLBW newborns mainly occurred 1 year after implementation of bnCPAP, early surfactant treatment, and rapid extubation strategy, and continued to show improving trends in respiratory outcomes during the subsequent 3 years, consistent with similar improvements reported by others after several years of use. ${ }^{11,17}$ Our study expands the VLBW population size and includes a larger number of VLBW babies and ELBW babies $<27$ weeks gestational age.

Although bnCPAP has been used successfully for respiratory support in VLBW newborns, ${ }^{3-5}$ safety issues have been raised. ${ }^{8,9}$ We examined common potential complications associated with positive airway pressure, including pulmonary hemorrhages, nasal abrasions, and pneumothoraces. ${ }^{8}$ We found that increases in nasal abrasions and increased use of postnatal steroids were not statistically significant. Hydrocortisone was used to decrease laryngeal edema on the day of extubation, but not for prolonged periods for amelioration of BPD. There were no significant differences in pulmonary hemorrhages or pneumothoraces.

The improvement we noted in mild or any stage ROP contrasts with an increase in mild ROP reported after a similar trial of bnCPAP. ${ }^{9}$ Increased attention to oxygen saturation parameters has been cited as contributing to reductions in ROP. ${ }^{18}$ However, target ranges of oxygen saturation remained unchanged before and after bnCPAP in our study. The early use of nasal CPAP, as in our study, has been associated with a reduction in ROP reported by others. ${ }^{19}$ There was no increase in necrotizing enterocolitis rates in our study, consistent with other reports. ${ }^{20} \mathrm{~A}$ significant increase in low-grade (1-2) IVH but not highgrade $(3-4)^{21}$ (despite the use of prophylactic indomethacin) or any-grade IVH found in our study has not previously been reported, and remains to be explored.

Improvements in BPD after initiating bnCPAP, in combination with early surfactant treatment and extubation, may reflect association rather than cause, due to confounding variables. For example, there were more transfers out of our unit (for surgical or multispecialty evaluation) in the post-bnCPAP years than in the pre-bnCPAP years. Nevertheless, the respiratory outcomes for these babies could be included in our study, because we had access to the shared database with the receiving institution.

There was a concomitant increase in subjects transferred into our unit for level 3 care from level 2 units where 
bnCPAP was not available. These outborn babies could have compromised respiratory outcomes of our bnCPAP cohort, as these babies were not offered the same delivery room management as our inborn population and tended to be placed on mechanical ventilation for transport. On arrival the transported babies who were breathing spontaneously were extubated to bnCPAP as quickly as possible, to minimize time on mechanical ventilation. The increase in babies transferred into our unit did not have a statistically significant impact on BPD in our logistic regression model.

Changes in neonatal care during this study included significant decreases in PDA ligations after the introduction of prophylactic indomethacin, ${ }^{22}$ increased use of prophylactic vitamin A to decrease $\mathrm{BPD},{ }^{23}$ and a decrease in prenatal steroid use. Controlling for these changes in a binary logistic regression model with BPD as the outcome variable confirmed the significant contribution of bnCPAP to an improved respiratory outcome. The model also highlights the importance of the decrease in PDA ligations as a factor in improving BPD. ${ }^{24}$ As expected, early estimated gestational age and male sex are associated with BPD.

Improved respiratory outcomes reported here may have been affected by more organized intubation and extubation practices and by delivery room management changes during the bnCPAP years. Also, an increased level of nursing and respiratory care required for successful bnCPAP may have improved outcomes, rather than bnCPAP alone. We think this is unlikely because we demonstrated here that babies in the pre-bnCPAP era were more likely to be intubated and remain on mechanical ventilation longer than babies in the post-bnCPAP years. Because of increased attention needed for ventilated babies, our nursing services routinely assign 1 nurse for each 1 or 2 ventilated babies, compared to assigning 1 nurse for 3 bnCPAP babies. In addition, the number of personnel in attendance at a VLBW newborn delivery (one respiratory therapist, nurse, and neonatologist) was the same during the 7 years of this study.

We have shown that early bnCPAP for spontaneously breathing babies is associated with a decrease in mechanical ventilation. Mechanical ventilation has been a well documented causal factor in pulmonary inflammation. ${ }^{25,26}$ Reduction in its use has not necessarily been associated with a concomitant reduction in BPD. ${ }^{8,9}$

BnCPAP may have advantages over other CPAP methods, ${ }^{27-29}$ having successfully reduced BPD to $4 \%$ at Columbia University. ${ }^{5,7} \mathrm{BnCPAP}$ promotes differentiation and maturation in fetal lungs. ${ }^{30}$ Airway vibrations caused by bubbling may improve lung mechanics $28,31,32$ and, in contrast to ventilator-driven nasal CPAP, improve oxygenation. ${ }^{33}$ In addition to bnCPAP we instituted early surfactant therapy in the delivery room, with rapid extubation to bnCPAP for babies with substantial respiratory distress. ${ }^{13,14}$ Our study did not explore whether other forms of nasal CPAP may be as efficacious as bnCPAP.
The improvements in respiratory outcomes associated with bnCPAP in VLBW babies in our study are consistent with the theory that prevention of alveolar atelectasis in surfactant-deficient lungs is better than rescuing alreadycollapsed lungs. ${ }^{13,20}$ The operative mechanisms include splinting open of the airway and increasing transpulmonary pressure. By increasing end-expiratory pressure, bnCPAP maintains lung volume ${ }^{34}$ and functional residual capacity, ${ }^{35}$ preventing intrapulmonary right-to-left shunting and avoiding mechanical ventilation. ${ }^{36}$

\section{Conclusions}

The results we report verify our hypothesis that the introduction of bnCPAP, combined with early surfactant use and rapid extubation when possible, was associated with a reduction in BPD in VLBW newborns. This reduction was statistically significant and remained significant when analyzed using logistic regression to account for other changes over the 7 years of the study. There were improvements in other measures of respiratory outcomes (time on mechanical ventilation, and discharged on oxygen supplementation and diuretic therapy). Improvement was also noted in the ELBW subset.

There was no increase in major complications. The beneficial outcomes reported here took 4 years to develop and required a substantial amount of time, effort, and coordination on the part of respiratory therapists, nurses, and physicians. The improvements in respiratory outcome we noted were associated with a comprehensive clinical approach that included bnCPAP, early surfactant use, and rapid extubation to bnCPAP. The role of reduced PDA ligation in this approach needs further exploration.

We recommend a randomized controlled trial of bnCPAP compared to other kinds of nasal CPAP designed to minimize mechanical ventilation.

\section{ACKNOWLEDGMENTS}

We thank JT Wung MD, Columbia University, New York, New York, for on-site demonstration and instruction in the use of bubble nasal CPAP; Kristen Brandt RN NNP for data collection and chart reviews; and Alan Spitzer MD, Pediatrix Medical Group, for thoughtful advice on the manuscript; and the neonatal ICU nurses, respiratory therapists, and staff at Memorial Hermann Southwest Hospital, for supporting this study.

\section{REFERENCES}

1. Martin JA, Kung H, Mathews TJ, Hoyert DL, Strobino DM, Guyer B, Sutton SR. Annual summary of vital statistics. Pediatrics 2008; 121(4):788-801.

2. Eichenwald EC, Stark AR. Management and outcomes of very low birth weight. N Engl J Med 2008;358(16):1700-1711.

3. Avery ME, Tooley WH, Keller JB, Hurd SS, Bryan MH, Cotton RB, et al. Is chronic lung disease in low birth weight babies preventable? A survey of eight institutions. Pediatrics 1987;79(1):26-30.

4. Horbar JD, McAuliffe TL, Adler SM, Albershelm S, Cassady G, Edwards W, et al. Variability in 28-day outcomes for very low birth 
weight infants: an analysis of 11 neonatal intensive care units. Pediatrics 1988;82(4):554-559.

5. Van Marter LJ, Allerd EN, Pagano M, Sanocka U, Parad R, Moore $\mathrm{M}$, et al. Do clinical markers of barotrauma and oxygen toxicity explain interhospital variation in rates of chronic lung disease? Pediatrics 2000;105(6):1194-1201.

6. Horbar JD, Soll RF, Edwards WH. The Vermont Oxford Network: a community of practice. Clin Perinatol 2010;37(1):29-47.

7. Ammari A, Suri M, Milisavjeric V, Sahri R, Bateman D, Sanocka U, et al. Variables associated with early failure of nasal continuous positive airway pressure in very low birth weight infants. J Pediatr 2005;147(3):341-347.

8. Morley CJ, Davis PG, Doyle LW, Brion LP, Hascoet JM, Carlin JB. Nasal CPAP or intubation at birth for very preterm infants. N Engl J Med 2008;358(7):700-708.

9. Nowadzky T, Pantoja A, Britton JR. Bubble continuous positive airway pressure, a potentially better practice, reduces the use of mechanical ventilation among very low birth weight infants with respiratory distress syndrome. Pediatrics 2009;123(6):1534-1540.

10. Aly $\mathrm{H}$. Is there a strategy for preventing bronchopulmonary dysplasia? Absence of evidence is not evidence of absence. Pediatrics 2007;119(4):818-820.

11. Aly H, Milner JD, Patel K, El-Mohandes AA. Does the experience with the use of nasal continuous positive airway pressure improve over time in extremely low birth weight infants? Pediatrics 2004;114(3):697-702.

12. Verder H, Robertson B, Greisen G, Ebbesen F, Albertsen P, Lundstrom K, Jacobsen T. Surfactant therapy and nasal continuous positive airway pressure for newborns with respiratory distress syndrome. Danish-Swedish Multicenter Study Group, N Engl J Med 1994;331(16): 1051-1055.

13. Rojas AM, Lozano JM, Rojas MX, Laughon M, Bose CL, Rondon MA, et al. Very early surfactant without mandatory ventilation in premature infants treated with early continuous positive airway pressure: a randomized, controlled trial. Pediatrics 2009;123(1):137-142.

14. Geary C, Caskey M, Fonseca R, Malloy M. Decreased incidence of bronchopulmonary dysplasia after early management changes, including surfactant and nasal continuous positive airway pressure treatment at delivery, lowered oxygen saturation goals, and early amino acid administration: a historical cohort study. Pediatrics 2008;121(1):89-96.

15. Fowlie PW, Davis PG, McGuire W. Prophylactic intravenous indomethacin for prevention of mortality and morbidity in preterm infants. Cochrane Database Syst Rev 2010;(7):CD000174.

16. Finer NN, Carlo WW, Walsh MC, Rich W, Gantz MG, Laptook AR, et al; the SUPPORT Study Group. Early CPAP versus surfactant in extremely preterm infants. N Engl J Med 2010;362(21):1970-1979.

17. Birenbaum HJ, Dentry A, Cirelli J, Helou S, Pane MA, Starr K, et al. Reduction in the incidence of chronic lung disease in very low birth weight infants: results of a quality improvement process in a tertiary level neonatal intensive care unit. Pediatrics 2009;123(1):44-50.

18. Vanderveen DK, Mansfield TA, Eichenwald EC. Lower oxygen saturation alarm limits decrease the severity of retinopathy of prematurity. J AAPOS 2006;10(5):445-448.

19. Kirchner L, Weninger M, Unterasinger L, Birnbacher R, Hayde M, Krepler R, Pollak A. Is the use of early nasal CPAP associated with lower rates of chronic lung disease and retinopathy of prematurity?
Nine years of experience with the Vermont Oxford Neonatal Network. J Perinat Med 2005;33(1):60-66.

20. Aly H, Massaro AN, Hammad TA, Narang S, Essers J. Early nasal continuous positive airway pressure and necrotizing enterocolitis in preterm infants. Pediatrics 2009;124(1):205-210.

21. Levene MJ, Fawer CL, Lamon RT. Risk factors in the development of intraventricular hemorrhage in the preterm neonate. Arch Dis Child 1982;57(6):410-417.

22. Couser RJ, Ferrara TB, Wright GB, Cabalka AK, Schilling CG, Hoekstra RE, Payne NR. Prophylactic indomethacin therapy in the first twenty-four hours of life for the prevention of patent ductus arteriosus in preterm infants treated prophylactically with surfactant in the delivery room. J Pediatr 1996;128(5):631-637.

23. Darlow BA, Graham PJ. Reduction in chronic lung disease and death in preterm infants. Cochrane Database Syst Rev 2002;(4):CD000501.

24. Raval MV, Laughton MM, Bose CL, Phillips JD. Patent ductus arteriosus ligation in premature infants: who really benefits and at what cost? J Pediatr Surg 2007;42(1):69-75.

25. Speer CP. New insights into the pathogenesis of pulmonary inflammation in preterm infants. Biol Neonate 2001;79(3-4):205-209.

26. Kotecha S. Lung growth: implications for the newborn infant. Arch Dis Child Fetal Neonatal Ed 2000;82(1):F69-F74.

27. De Paoli AG, Morley C, Davis PG. Nasal CPAP for neonates: what do we know in 2003? Arch Dis Child Fetal Neonatal Ed 2003;88(3): F168-F172.

28. Lee KS, Dunn MS, Fenwick M, Shennan AT. A comparison of underwater continuous positive airway pressure (CPAP) with ventilator-derived CPAP in premature neonates ready for extubation. Biol Neonate 1998;73(2):69-75

29. Gupta S, Sinha SK, Tin W, Donn SM. A randomized trial of postextubation bubble continuous positive airway pressure versus infant flow driver continuous positive airway pressure in preterm infants with respiratory distress syndrome. J Pediatr 2009;154(5):645-650.

30. Zhang S, Garbutt V, McBride JT. Strain-induced growth of the immature lung. J Appl Physiol 1996;81(4):1471-1476.

31. Thome U, Pohlandt F. Effect of Ti/Te ratio on mean intratracheal pressure in high frequency oscillatory ventilation. J Appl Physiol 1998;84(5):1520-1527.

32. Reddy PI, Al-Jumally AM, Bold GT. Dyanamic surface tension of natural surfactant under superimposed oscillations. J Biomech 2011; 44(1):156-163.

33. Courtney SE, Kahn DJ, Singh R, Habib RH, Bubble and ventilatordriven continuous positive airway pressure in premature infants: work of breathing and gas exchange. J Perinatol 2011;31(1):44-50.

34. Pillow JJ, Hillman N, Moss TJ, Polglase G, Bold G, Beaumont C, et al. Bubble continuous positive airway pressure enhances lung volume and gas exchange in preterm lambs. Am J Respir Crit Care Med 2007;76(1):63-69.

35. Lista G, Castoldi F, Cavigioli F, Blanchi S, Fontani P. Alveolar recruitment in the delivery room. J Matern Fetal Neonatal Med 2012; 25(Suppl 1):39-40.

36. Diblasi RM. Nasal continuous positive airway pressure (CPAP) for the respiratory care of the newborn infant. Respir Care 2009; 54(9):1209-1235.

This article is approved for Continuing Respiratory Care Education credit. For information and to obtain your CRCE

(free to AARC members) visit www.rcjournal.com

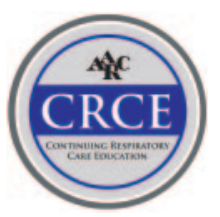

